\title{
Effect of Boswellia serrata extract on tissue inflammation and white blood cells responses of spinal cord injury in rat model
}

\author{
Moosa Javdani $^{* \bullet}$, Mojtaba Ahmadi Dastjerdi ${ }^{2}$, Sadegh Shirian ${ }^{3}$ \\ ${ }^{1}$ Department of Clinical Sciences, Faculty of Veterinary Medicine, Shahrekord University, Shahrekord, Iran \\ ${ }^{2}$ Faculty of Veterinary Medicine, Shahrekord University, Shahrekord, Iran \\ ${ }^{3}$ Department of Pathobiology, Faculty of Veterinary Medicine, Shahrekord University, Shahrekord, Iran
}

\section{A R T I C L E I N F O}

\section{Article Type:}

Original Article

\section{Article History:}

Received: 10 May 2018

Accepted: 19 September 2018

\section{Keywords}

Spinal cord injury

Boswellia serrata

Rat

Inflammation

Traditional medicine

\begin{abstract}
A B S T R A C T
Introduction: The severe inflammatory responses that occurs after traumatic spinal cord injury (SCI) is with great strength related to the further tissue damage. As such, developmental strategies have been investigated, aimed at restricting inflammation and encouraging regeneration of injured neural tissue. One of those encouraging strategies is administration of traditional medicinal plants. The current study was conducted to evaluate the neuroprotective effects of Boswellia serrata extract on the neuronal tissue inflammation and white blood cells (WBCs) responses in rats with SCI.

Methods: Forty adult female rats were randomly assigned into 2 equal groups as experimental and control groups. Under general inhalation anesthesia, in both groups, SCI was created, at T9-10 level of the column. On the third day after the operation, an oral supplement of $B$. serrata extract was administered to the experimental group at $100 \mathrm{mg} / \mathrm{kg} / \mathrm{d}$. The histology of the site of injury and changes in the WBCs were examined in both groups at different presurgical and post-surgical times.

Results: The total population of WBCs in the current study was significantly less in the experimental group, compared to the control group at third and fourth weeks of the study which could be related to the anti-inflammatory effects of $B$. serrata extract. Histopathological evaluation of lesion sites confirmed the reduced inflammatory responses in the experimental group compared to the control group $(P<0.05)$.

Conclusion: The decrease in the number of inflammatory cells after oral consumption of $B$. serrata extract and the histopathological results confirm the neuroprotective effects of this extract.
\end{abstract}

Implication for health policy/practice/research/medical education:

Anti-inflammatory impacts of oral consumption of Boswellia serrata extract can control secondary injury associated with SCI.

Please cite this paper as: Javdani M, Ahmadi-Dastjerdi M, Shirian S. Effect of Boswellia serrata extract on tissue inflammation and white blood cells responses of spinal cord injury in rat model. J Herbmed Pharmacol. 2018;7(4):273-279. doi: 10.15171/ jhp.2018.41.

\section{Introduction}

Spinal cord injury (SCI) as a worldwide form of neurological damage can destroy central nervous system of patients, result in high rates of disability and create considerable medical costs $(1,2)$. Trauma is one the most common causes of SCI; therefore, in addition to more than 12000 subjects that are affected once a year in the United States, many more are influenced in developing countries, additionally (3). Devastating trauma leads to primary injury, by the focal destruction of neural substance and secondary complications that can continue to weeks, and are related to losing strength of blood-spinal cord barrier, neuronal damage, oxidative stress, neuro-inflammation, and ischemic abnormality $(4,5)$.

These problems as a detrimental cascade, can be managed by pharmacological intercessions, but there has been little success or no definite curative therapy in this regard (6). Alternative strategies for SCI interventions such as traditional herbal medicine, with many thousands years history, would be valuable in the prevention and treatment of SCI.

For thousands of years, Boswellia species or frankincense has been used for medical reasons. In conventional Asian medicine, Boswellia species are a therapeutic element 
applied by diseases of the nervous system; Boswellia species were furthermore administrated for the treatment of various diseases of the gastrointestinal tract, and for gynecological plans (7).

Boswellia serrata and its extracts are traditionally used to treat different types of blood disorders, inflammatory health conditions, cardiac debility, and pain (8). There are various scientific investigations about pharmacological actions of $B$. serrata-gum resin. Gummy exudates of $B$. serrata stem bark or its great constituents, boswellic acids possess anti-inflammatory $(9,10)$, anti-cancerous (11) and anti-ulcerous (12) roles.

Boswellia with its neuroprotective activity increases structural development of new nerve networks (13). It also impedes degenerative alternations in the hippocampus, which is the memory-processing region in the brain (14). Therefore, some studies suggest that B. serrata and its compounds need to be scientifically investigated in neurophysiology and feasibly for the future handling of neurodegenerative disorders $(7,15)$. Toxicology academic works of $B$. serrata resin directed on animals showed no notable histopathological, genotoxic, and hematological changes after consumption of this resin at doses up to $1000 \mathrm{mg} / \mathrm{kg}$. Furthermore, the adverse effects are insignificant in humans, and occasionally nausea, acid reflux and digestive complaints have been reported in some consumers $(16,17)$.

Based on the above mentioned information, the current study was conducted to evaluate neuroprotective effects of $B$. serrata extract on the neuronal tissues in experimental SCI in rat model.

\section{Materials and Methods}

Drug preparation

Boswellia serrata was bought from Iran Darouk Pharmaceutical Co., Iran. After grinding of B. serrata, $1000 \mathrm{~g}$ of its powder was put in a clean 10-litre flask and mixed with $8 \mathrm{~L}$ of $70 \%$ ethanol for a period of 48 hours at indoor temperature. The final mixture was then filtered and dried out using a rotary evaporator at a temperature below $50^{\circ} \mathrm{C}$ until its volume reduced to $5 \%$ of its original volume $(18,19)$. Subsequently, the residual content was kept at refrigerator temperature.

\section{Animals}

Forty adult female rats (Sprague-Dawley), weighing approximately 250-300 g were assigned in the current study. The animals were arbitrarily allocated into experimental $(n=20)$ and control $(n=20)$ groups. All rats were retained under controlled states at room temperature, with conventional humidity and a $12 \mathrm{~h}$ light cycle, and allowed free access to food and water.

Animal model establishment and drug treatment All rats received premedication regimen subcutaneously (Xylazine $10 \mathrm{mg} / \mathrm{kg}$, Alfasan) and after 10 minutes anesthetized with isoflurane (Terrel Isoflurane; PCC Inc.). Initially, the rats were placed on the operating room table and a midline dorsal area was prepared, surgically. A midline surgical cut was made in skin at level of T8T11, and the bilateral para-spinal muscles exactly were dissected. In two groups at T9-10 level of column, due to dorsal laminectomy, cord compression as a SCI was made, using aneurysm clip for 60 seconds $(20,21)$.

Hind limb locomotor deficiency and tail paralysis resulted from SCI, confirmed the efficacy of the aneurysm clip compression technique. After exact control of bleeding, paravertebral fascia and skin were sutured in the simple continuous pattern (21).

Manual expression of urinary bladders, twice daily, was performed at the first three days after surgery and additionally all rats received enrofloxacin $(2.5 \mathrm{mg} / \mathrm{kg}$; Enrofloxacin 10\%; Amineh Gostar Co.), twice daily for five postoperative days, in order to avoid infection. Seventy-two hours later from the cord compression, the experimental group's animals received $100 \mathrm{mg} /$ $\mathrm{kg}$ B. serrata extract (Daily for 4 weeks), by traditional orogastric gavage.

\section{Histopathological assessment}

At different times post-surgery (day 3, 7, 21, and 28), after sacrifice of the rats, a dorsal laminectomy was performed at the total lumbar and thoracic vertebrae levels and spinal cord tissue samples were collected for microscopic examination. The spinal cord samples of all animals in both groups were embedded in paraffin and fixed with $10 \%$ buffered formalin for 24 hours. Five $\mu$ m-thick serial sections were cut from the paraffin blocks, using a microtome and stained with hematoxylin-eosin (H\&E) and toluidine blue (TB) for routine histopathological examinations. Histopathological sections were subjected to descriptive analyses, by an experienced Histopathologist, blinded to the groups and study design.

\section{Blood works}

In addition, a number of blood samples were accumulated by heart puncture at days $3,7,21$, and 28 , postoperatively, just before sacrificing of the rats, and total and differential White blood cell (WBC) count, and neutrophil/ lymphocyte ratios (N/L ratio) were evaluated.

\section{Statistical analysis}

The mean of the measured parameters (mean \pm SEM) were compared between the control and experimental groups, using an independent $t$ test. Data changes in each group were analyzed, using the ANOVA test. $P<0.05$ was regarded as statistically significant.

\section{Results}

Histopathological assessment and cell counts

Histological changes in both control and experimental groups at third day post-operation revealed apparent 
hemorrhage and severe inflammation at the injured site (Figure 1).

Neural tissue sections from the control group in first week post-injury showed extensive necrosis with inflammation and obvious hemorrhagic area but less than third day postoperation. Necrotic and degenerated neurons observed at the injured site (Figure 2).

Histological features of animals in experimental group in first week after surgery indicated degenerated and necrotic neurons with moderate hemorrhage and inflammation at the lesion site (Figure 3).

During the third week, mild to severe hemorrhage and inflammation, accompanied with notable neuronal necrosis were observed in the control group (Figure 4), while considerable reduction in inflammation and hemorrhage also with total necrosis of gray matter of cord were noticed in the experimental group (Figure 5).

At 28th day post-injury in the control group, minimal hemorrhage, and mild inflammation were noted, while neuronal necrosis in both gray and white matter was observed (Figure 6). However, in the experimental group, the smallest amount of inflammation and hyperemia accompanied with little necrotic neuronal zones was detected at the lesion site (Figure 7). In sum, descriptive data revealed a considerabe decrease in inflammation and hemorrhage, during the third and fourth weeks, in the experimental group, compared to the control group.

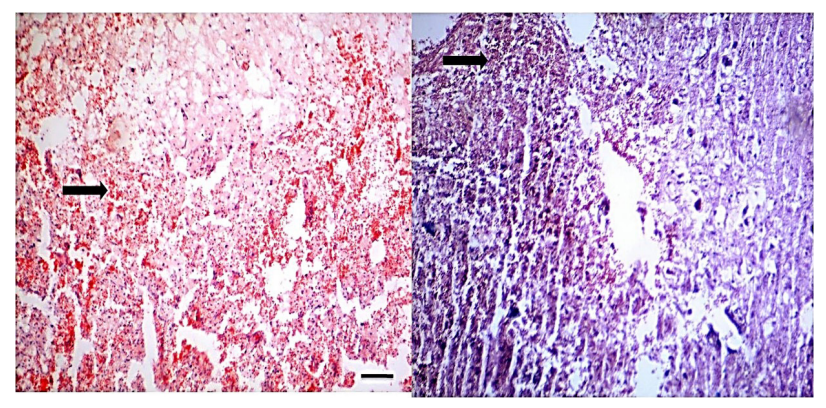

Figure 1. Day 3 of post-operation in both groups; severe hemorrhage (arrow) around the lesion; H\&E stain (left), TB stain (right); scale bar $=56 \mu \mathrm{m}$

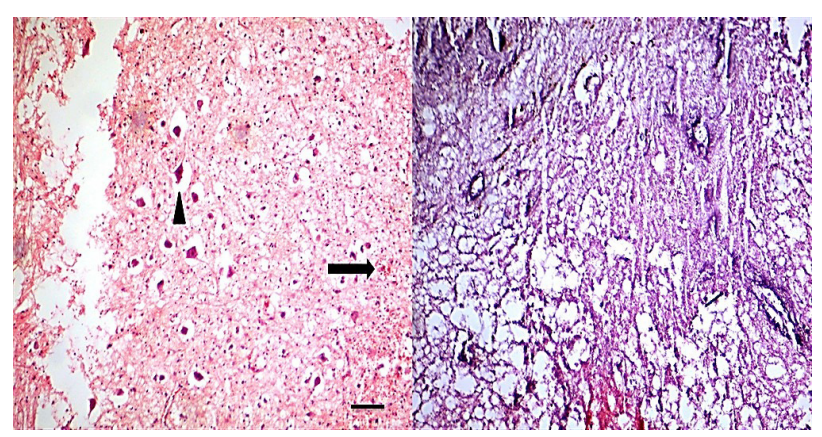

Figure 2. Histological structures in the control group at 1st week after surgery; Inflammation and obvious hemorrhage (arrow) with neuronal necrosis (arrowhead) at the lesion site. H\&E stain (left fig.), TB stain (right fig.); scale bar $=56 \mu \mathrm{m}$

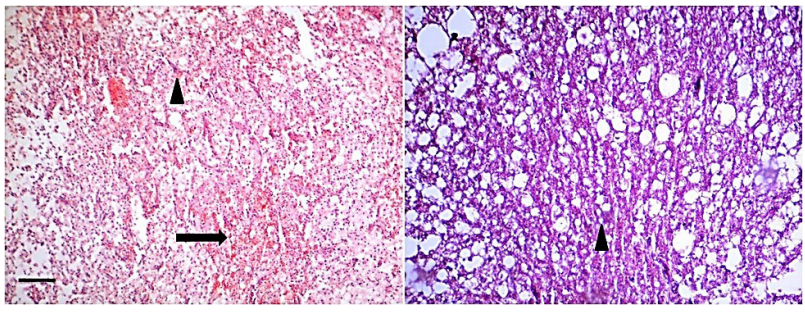

Figure 3. Histological features in the experimental group at first week after surgery; moderate inflammation and hemorrhage (arrow) and necrosis (arrowhead) around the injured site; H\&E stain (left), TB stain (right); scale bar $=56 \mu \mathrm{m}$.

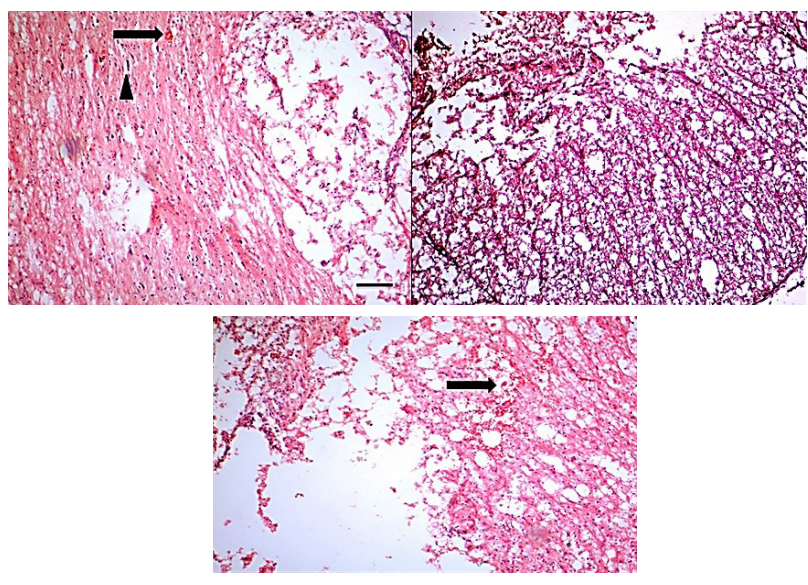

Figure 4. Histopathological changes in the control group at 3rd week after operation; Hemorrhage (arrow) and inflammation accompanied with neuronal necrosis (arrowhead) in the defected site; H\&E stain (left and below), TB stain (right); scale bar $=56 \mu \mathrm{m}$.
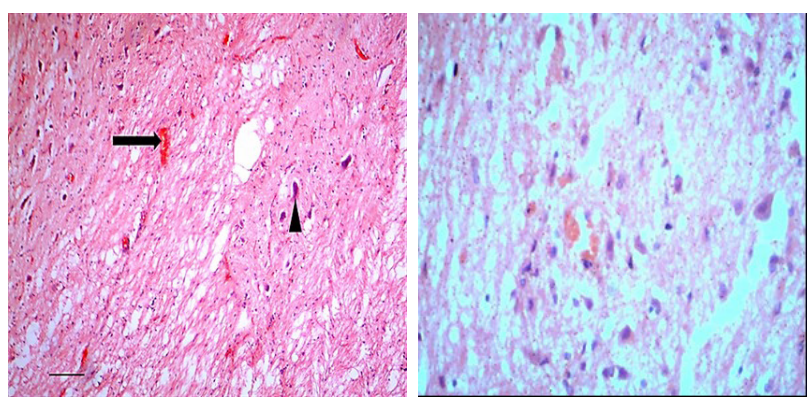

Figure 5. Histopathological findings in the experimental group at 3rd week post-surgery; hemorrhage (arrow) and neuronal necrosis (arrowhead) in the vicinity of the lesion; H\&E stain (both figs.); scale bar $=56 \mu \mathrm{m}$.

\section{Leukogram analysis}

Mean $( \pm$ SEM $)$ of the total Wright-Giemsa stained white blood cell (tWBC) of the different times, in both groups are delineated in Figure 8. There was no significant difference between this parameter in day 3 and week 1 of the study $(P>0.05)$. Analyzed data revealed a significant decrease in tWBC, during the third and fourth weeks, in the experimental group, compared to the control group $(P<0.05)$.

Figures 9 to 11 show neutrophils, lymphocyte, and 


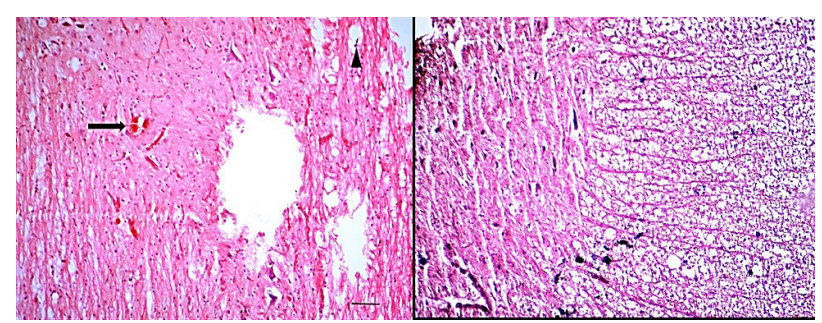

Figure 6. Histological findings in the control group at 4th week after surgery; Neuronal necrosis (arrowhead) and hemorrhage (arrow) at the lesion site; H\&E stain (left), TB stain (right); scale bar= $56 \mu \mathrm{m}$.

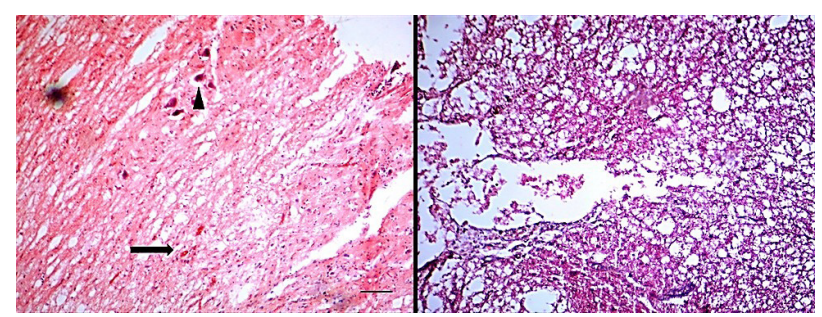

Figure 7. Histological findings in the experimental group at 4th week after surgery; minimal hyperemia (arrow) and mild inflammation with necrotic neurons (arrowhead); H\&E stain (left), TB stain (right); scale bar $=56 \mu \mathrm{m}$.

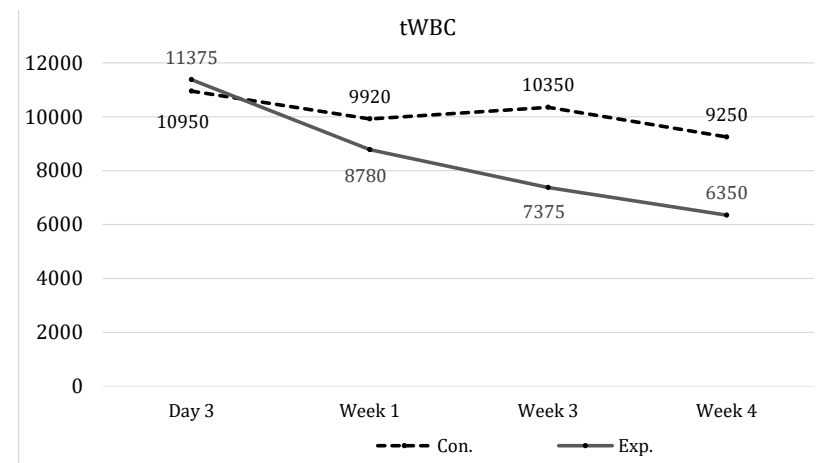

Figure 8. tWBC $\left(10^{6} / \mathrm{L}\right)$ changes during the various times in both groups; tWBC: total White Blood Cell; Con.: Control group, Exp.: Experimental group.

monocyte changes during the different times of the current study in the control and experimental groups. There were significant differences between mean $( \pm$ SEM) of the neutrophils in week 1 and week 4 of the study $(P>0.05)$.

The analyzed results revealed a significant reduction between the mean $( \pm$ SEM) of lymphocyte, between the control and experimental groups in day 3 and week 4 after operation. Twenty-eight days after surgery, the mean $( \pm$ SEM $)$ of monocyte showed remarkable differences $(P=0.02)$, between both groups. Evaluation of $\mathrm{N} / \mathrm{L}$ ratio in the 2 groups demonstrates significant difference during weeks 1 and 4 .

The presented figures delineated alternations of inflammatory cells (lymphocytes, neutrophils, and

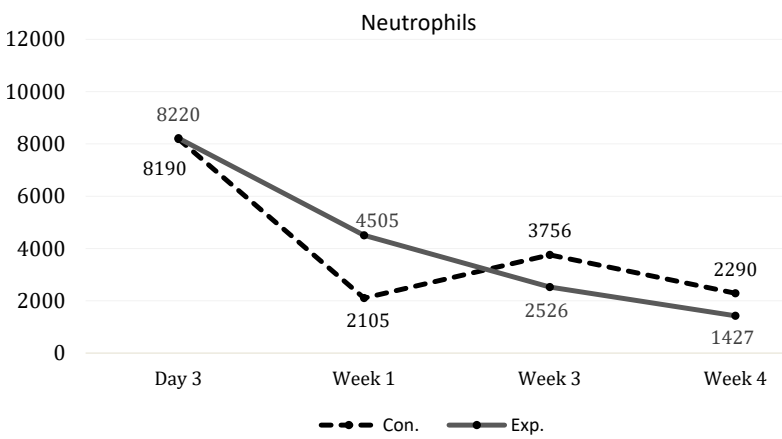

Figure 9. Neutrophils $\left(10^{6} / \mathrm{L}\right)$ changes during the different times in both groups; Con.: Control group, Exp.: Experimental group.

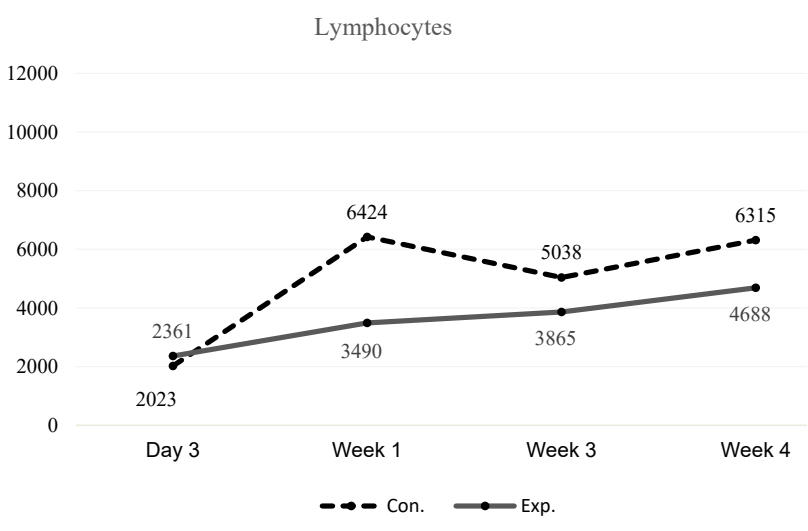

Figure 10. Lymphocyte $\left(10^{6} / \mathrm{L}\right)$ changes during the different times in both groups. Con.: Control group, Exp.: Experimental group.

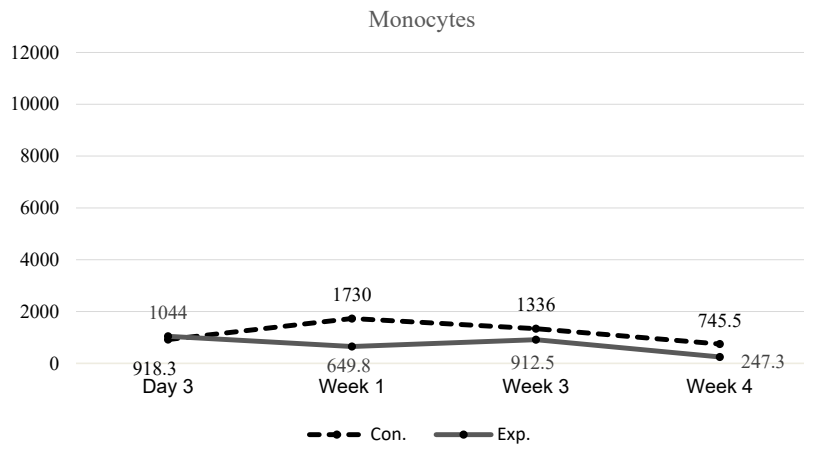

Figure 11. Monocyte $\left(10^{6} / \mathrm{L}\right)$ alternations at the different times in the control and experimental groups; Con.: Control group, Exp.: Experimental group.

monocytes), at different times, in the control and experimental groups. These figures show noticable decrease of neutrophils over the 7 days after spinal injury $(P<0.05)$, resulting in an obvious decrease of tWBC due to surgery.

\section{Discussion}

Over the past few years, the extent of herbal extracts utilization with neuroprotective activities, such as Boswellia species in biological needs have been widened. 
For that reason, the contemporary study was conducted to decrease the inflammation and also to promote myelination associated with oral medication of B. serrata extract, in the rat suffered from compressive SCI. Twentyeight days administration of this extract in the affected adult female rats, showed interesting findings that the extract could limit secondary complications following SCI.

Trauma, as a mechanical damage, compresses the spinal cord and disfigures the cord vessels and produces hemorrhage at the contusion site, and after a period of time induces edema and regional ischemia $(22,23)$.

Secondary complications will happen after few minutes and move forward several weeks following SCI, and the correlated events, such as inflammation, gliosis, and neuronal degeneration cause severe functional abnormalities. Post-traumatic inflammatory environment has associated with active microglia and astrocytes, and as well penetrated macrophages, which strongly make it possible to develop secondary damages. The angiogenic reactions and reconstruction of vessels increase secondary injuries. Therefore, restriction of secondary injuries leads to limiting of neurodegeneration, and subsequently functional recovery attains more rapid $(22,24)$. SCI induces immune depression syndrome, which is due to disturbance of the sympathetic nervous system and impairment of the immune system function (25).

Additionally, general inflammatory responses, because of SCI, persuade an increase of inflammatory cells into the circulation and secondary tissues, activation of immune cells, and pro-inflammatory cytokine secretion, all of which intervene with the pathogenesis of various organs after SCI (22). Evaluated leukograms in the current experiment revealed a significant decrease in total WBCs and neutrophils during the third and fourth weeks, in the experimental group, compared to the control group. Furthermore, histological sections during these weeks confirmed notable reduction of inflammation in the experimental group in comparison to the control group. The advantage of $\mathrm{N} / \mathrm{L}$ ratio is related to anticipation of systemic inflammation and stress $(26,27)$. In fact, it is index of a disorganized cell-mediated immunity, related to the systemic inflammation (28). Our data showed a notable decrease of $\mathrm{N} / \mathrm{L}$ ratio in the experimental and control groups that is related to significant increase of neutrophils at the day 7. There was no significant difference between two groups about this value in various times.

An interesting point to consider is that the total population of WBCs in the current study was significantly less in the experimental group, compared to the control group at third and fourth weeks of the study which is related to the anti-inflammatory effects of $B$. serrata extract. Histopathological evaluation of lesion sites confirmed this desirable effect. Similar other studies, our data reveal that neutrophils are needed for encouraging functional recovery after spinal cord damage. They are initial inflammatory cells which appear at the lesion site and act by different mechanisms, such as releasing angiogenic factors, to induce inflammation-mediated tissue remodeling $(29,30)$.

We did not find any studies that investigate effects of $B$. serrata extract on the neuronal cells in traumatic SCI. A few available studies just evaluated effects of this medicine herb on the brain. Resins of Boswellia species act as a natural anti-inflammatory product that has been administrated in some centuries (9).

Several found compounds of Boswellia have effects on the immune system in different routes. Boswellic acids, betaboswellic acid (BA), 3-acetyl-beta-boswellic acid (ABA), 11-keto-boswellic acid (KBA) and 3-acetyl-11-keto-betaboswellic (AKBA), are named as the major ingredients of $B$. serrata (31). AKBA, as a potent component of extract of $B$. serrata, move across the blood brain barrier (32) and is able to inspire its anti-inflammatory effects. Boswellic acids (AKABA) inhibit 5-lipoxygenase enzyme so suppress leukotriene biosynthesis. It has been revealed that boswellic acid decreases some interleukins (1, 2, 4, $6,10,12)$ and IFN $\gamma$, induces down regulation of Tumor necrosis factor (TNFa), and puts down WBC migration. Also, B. serrata suppresses mast cell degranulation and induction of monocytes and macrophages and inhibits pathways of complement directly or indirectly (33).

It has been reported that boswellic acids through activating protein kinase- $\mathrm{C}$, is effective in learning and memory storage and cause synaptic plasticity in the hippocampus $(34,35)$. Another identified constituent in Boswellia resin is incensole-acetate, which shows antiinflammatory activities on the central nervous system (CNS) and has been shown antianxiety and in addition anti-depression impacts. Previous studies have revealed that incensole-acetate holds back degenerative changes in the hippocampus by increase of calcium influx and releasing of calcium dependent-neurotransmitters in the brain $(13,14,36)$. So, it seemed that Boswellia serrata extract by inhibition of different enzymes of the arachidonic acid cascade including lipoxygenases and cyclooxygenases potentially are able to control secondary injuries of compressed spinal cord. Therefore, evaluation of these enzymes in the future is recommended.

\section{Conclusion}

Examined histologic sections and analyzed systemic WBC alternations in the experimental group of the present study confirmed anti-inflammatory effects of oral consumption of Boswellia serrata extract in the rats suffered traumatic spinal cord damage.

\section{Authors' contributions}

MJ conducted the full work and performed the experiments. MAD participated in the clinical and 
laboratory processes. SS gave histopathological support. All authors have read and approved the submission of this paper.

\section{Conflict of interests}

The authors declare that there are no conflicts of interest associated with this manuscript.

\section{Ethical considerations}

All investigational procedures used in this study were reviewed and approved by the Council of Department of Veterinary Clinical Sciences of the Shahrekord University (170-572).

\section{Funding/Support}

None.

\section{References}

1. Ackery A, Tator C, Krassioukov A. A global perspective on spinal cord injury epidemiology. J Neurotrauma. 2004;21(10):1355-70. doi: 10.1089/neu.2004.21.1355.

2. van den Berg ME, Castellote JM, Mahillo-Fernandez I, de Pedro-Cuesta J. Incidence of spinal cord injury worldwide: a systematic review. Neuroepidemiology. 2010;34(3):18492; discussion 92. doi: 10.1159/000279335.

3. Devivo MJ. Epidemiology of traumatic spinal cord injury: trends and future implications. Spinal Cord. 2012;50(5):36572. doi: 10.1038/sc.2011.178.

4. Anwar MA, Al Shehabi TS, Eid AH. Inflammogenesis of secondary spinal cord injury. Front Cell Neurosci. 2016;10:98. doi: 10.3389/fncel.2016.00098.

5. Hausmann ON. Post-traumatic inflammation following spinal cord injury. Spinal Cord. 2003;41(7):369-78. doi: 10.1038/sj.sc.3101483.

6. Wyndaele M, Wyndaele JJ. Incidence, prevalence and epidemiology of spinal cord injury: what learns a worldwide literature survey? Spinal Cord. 2006;44(9):523-9. doi: 10.1038/sj.sc.3101893.

7. Hamidpour R, Hamidpour S, Hamidpour M, Shahlari M. Frankincense (rǔ xiāng; Boswellia species): from the selection of traditional applications to the novel phytotherapy for the prevention and treatment of serious diseases. J Tradit Complement Med. 2013;3(4):221-6. doi: 10.4103/2225-4110.119723.

8. Paranjpe P. S'allaký - Boswellia serrata. In: Indian Medicinal Plants - Forgotten Healers: A Guide to Ayurvedic Herbal Medicine. Delhi: Dehli Chaukhamba Sanskrit Pratishthan Publishers; 2001:233-4.

9. Ammon HP. Boswellic acids in chronic inflammatory diseases. Planta Med. 2006;72(12):1100-16. doi: 10.1055/s2006-947227.

10. Shen T, Lou HX. Bioactive constituents of myrrh and frankincense, two simultaneously prescribed gum resins in Chinese traditional medicine. Chem Biodivers. 2008;5(4):540-53. doi: 10.1002/cbdv.200890051.

11. Upaganlawar A, Ghule B. Pharmacological activities of Boswellia serrata Roxb. - mini review. Ethnobotanical Leaflets. 2009;13(6):766-74.

12. Singh S, Khajuria A, Taneja SC, Khajuria RK, Singh J, Johri
RK, et al. The gastric ulcer protective effect of boswellic acids, a leukotriene inhibitor from Boswellia serrata, in rats. Phytomedicine. 2008;15(6-7):408-15. doi: 10.1016/j. phymed.2008.02.017.

13. Moussaieff A, Shein NA, Tsenter J, Grigoriadis S, Simeonidou C, Alexandrovich AG, et al. Incensole acetate: a novel neuroprotective agent isolated from Boswellia carterii. J Cereb Blood Flow Metab. 2008;28(7):1341-52. doi: $\quad 10.1038 / j c b f m .2008 .28$.

14. Ring RH, Alder J, Fennell M, Kouranova E, Black IB, Thakker-Varia S. Transcriptional profiling of brain-derivedneurotrophic factor-induced neuronal plasticity: a novel role for nociceptin in hippocampal neurite outgrowth. J Neurobiol. 2006;66(4):361-77. doi: 10.1002/neu.20223.

15. Hosseini Sharifabad M, Esfandiary E. A morphometeric study on CA3 hippocampal field in young rats following maternal administration of Boswellia serrata resin during gestation. Iran J Basic Med Sci. 2007;10(3):176-82. doi: 10.22038/ijbms.2007.5292.

16. Singh GB, Atal CK. Pharmacology of an extract of salai guggal ex-Boswellia serrata, a new non-steroidal antiinflammatory agent. Agents Actions. 1986;18(3-4):407-12.

17. Sharma R, Singh S, Singh GD, Khajuria A, Sidiq T, Singh SK, et al. In vivo genotoxicity evaluation of a plant based antiarthritic and anticancer therapeutic agent boswelic acids in rodents. Phytomedicine. 2009;16(12):1112-8. doi: 10.1016/j.phymed.2009.06.009.

18. Siahpoosh A, Mehrpeyma M. Antioxidant effects of Albizia lebbek and Prosopis julifora barks. Int J Biosci. 2014;5(9):273-84.

19. Majdinasab N, Siahpush A, Mousavinejad SK, Malayeri A, Sajedi SA, Bizhanzadeh P. Effect of Boswellia serrata on cognitive impairment in multiple sclerosis patients. J Herb Med. 2016;6(3):119-27. doi: 10.1016/j.hermed.2016.05.003.

20. Onifer SM, Rabchevsky AG, Scheff SW. Rat models of traumatic spinal cord injury to assess motor recovery. Ilar j. 2007;48(4):385-95.

21. Erbayraktar Z, Gokmen N, Yilmaz O, Erbayraktar S. Experimental traumatic spinal cord injury. Methods Mol Biol. 2013;982:103-12. doi: 10.1007/978-1-62703-308-4_6.

22. Sun X, Jones ZB, Chen XM, Zhou L, So KF, Ren Y. Multiple organ dysfunction and systemic inflammation after spinal cord injury: a complex relationship. J Neuroinflammation. 2016;13(1):260. doi: 10.1186/s12974-016-0736-y.

23. Ropper AH. Traumatic injuries of the head and spine. In: Braunwald E, Fauci AS, Kasper DL, Hauser SL, Longo DL, Jameson JL, eds. Harrison's Principles of Internal Medicine. New York: McGraw-Hill; 2001:2441-2.

24. Profyris C, Cheema SS, Zang D, Azari MF, Boyle K, Petratos S. Degenerative and regenerative mechanisms governing spinal cord injury. Neurobiol Dis. 2004;15(3):415-36. doi: 10.1016/j.nbd.2003.11.015.

25. Lucin KM, Sanders VM, Jones TB, Malarkey WB, Popovich PG. Impaired antibody synthesis after spinal cord injury is level dependent and is due to sympathetic nervous system dysregulation. Exp Neurol. 2007;207(1):75-84. doi: 10.1016/j.expneurol.2007.05.019.

26. Zahed NS, Karimi Mahali Z. Evaluation of cutoff point and power of neutrophil to lymphocyte ratio in diagnosing chronic inflammation in end-stage renal disease (ESDR) 
patients. Medical Journal of Mashhad University of Medical Sciences. 2015;58(6):289-94.

27. Al-Hussain F, Alfallaj MM, Alahmari AN, Almazyad AN, Alsaeed TK, Abdurrahman AA, et al. Relationship between neutrophil-to-lymphocyte ratio and stress in multiple sclerosis patients. J Clin Diagn Res. 2017;11(5):Cc01-cc4. doi: $10.7860 / j \mathrm{jdr} / 2017 / 24388.9764$.

28. McMillan DC. Systemic inflammation, nutritional status and survival in patients with cancer. Curr Opin Clin Nutr Metab Care. 2009;12(3):223-6. doi: 10.1097/ MCO.0b013e32832a7902.

29. Schruefer R, Lutze N, Schymeinsky J, Walzog B. Human neutrophils promote angiogenesis by a paracrine feedforward mechanism involving endothelial interleukin-8. Am J Physiol Heart Circ Physiol. 2005;288(3):H1186-92. doi: 10.1152/ajpheart.00237.2004.

30. Neirinckx V, Coste C, Franzen R, Gothot A, Rogister B, Wislet S. Neutrophil contribution to spinal cord injury and repair. J Neuroinflammation. 2014;11:150. doi: 10.1186/ s12974-014-0150-2.

31. Jauch J, Bergmann J. An efficient method for the large- scale preparation of 3-o-acetyl-11-oxo- $\beta$-boswellic acid and other boswellic acids. European J Org Chem. 2003;2003(24):4752-6. doi: 10.1002/ejoc.200300386.

32. Kruger P, Daneshfar R, Eckert GP, Klein J, Volmer DA, Bahr $\mathrm{U}$, et al. Metabolism of boswellic acids in vitro and in vivo. Drug Metab Dispos. 2008;36(6):1135-42. doi: 10.1124/ dmd.107.018424.

33. Ammon HP. Modulation of the immune system by Boswellia serrata extracts and boswellic acids. Phytomedicine. 2010;17(11):862-7. doi: 10.1016/j.phymed.2010.03.003.

34. Nguyen PV, Woo NH. Regulation of hippocampal synaptic plasticity by cyclic AMP-dependent protein kinases. Prog Neurobiol. 2003;71(6):401-37. doi: 10.1016/j. pneurobio.2003.12.003.

35. Alkon DL, Sun MK, Nelson TJ. PKC signaling deficits: a mechanistic hypothesis for the origins of Alzheimer's disease. Trends Pharmacol Sci. 2007;28(2):51-60. doi: 10.1016/j.tips.2006.12.002.

36. Guyton AC, Hall JE. Text Book of Medical Physiology. Philadelphia: Saunders; 2011:751-2. 